\title{
Phytochemical Screening and Antibacterial Activity of Kratom Leaf (Mitragyna speciosa Korth.) Against Aeromonas hydrophilla
}

\author{
Eki Juanda ${ }^{*}$, Sri Andayani², Maftuch ${ }^{2}$ \\ ${ }^{1}$ Master Program of Aquaculture, Faculty of Fisheries and Marine Sciences, University of Brawijaya, Malang, Indonesia \\ ${ }^{2}$ Faculty of Fisheries and Marine Sciences, University of Brawijaya, Malang, Indonesia
}

\begin{abstract}
Kratom (Mitragyna speciosa) is an indigenous tropical herbal plant to the Northern Malay Peninsula and Thailand. Empirically kratom leaves have several properties as herbal medicines. Currently, the treatment of diseases caused by bacteria that are resistant to antibiotics requires new compounds that have high potential. The material studied was kratom leaf extract. The solvent used for extraction is methanol. Phytochemical screening carried out includes the examination of alkaloids, flavonoids, steroids/terpenoids, phenols, tannins, and saponins. The test bacteria used was Aeromonas hydrophilla. The medium used is Nutrient Agar (NA). $\mathrm{NaCl} 0.9 \%$ as a bacterial suspension. Testing the antibacterial activity carried out with 10 (ten) variations of concentration namely $3 \%, 6 \%, 9 \%, 12 \%, 15 \%, 18 \%, 21 \%$, $24 \%, 27 \%$ and $30 \%$. Fresh kratom leaf is collected and then wet sorted. The extraction process was using the method of maceration. This study aims to analyze the antibacterial activity of kratom leaf, measure the secondary compounds of kratom leaf extract, and measure the best concentration to kill Aeromonas hydrophilla. The extraction process obtained blackish-brown extract with 62.27 grams of extract (31.14\%). Secondary metabolites of kratom leaf extract show positive results of alkaloid, saponins, tannins, phenolics, steroids, and triterpenoids. Antibacterial activity against Aeromonas hydrophila which is characterized by a kill zone around the paper disc with the best concentration that shows a wide killing zone was $24 \%$ of the extract.
\end{abstract}

Keywords: Antibacterial, Extract, Kratom, Mitragynine, Phytochemical Screening.

\section{INTRODUCTION}

Kratom (Mitragyna speciosa) is a tropical herbal plant indigenous to the Northern Malay Peninsula and Thailand [1]. In Indonesia, Kratom is a typical plant of Kalimantan, especially in Putusibau, West Kalimantan. The native society knows kratom leave as Purik leaf [2]. Generally, kratom consumed by chewed up, smoked as cigarettes, and drink as a tea [3].

Empirically kratom leaves have several properties as herbal medicines, including as a poultice on wounds, fever medication, relieve muscle pain, reduce appetite, and treat diarrhea $[1,4]$. Several studies on the pharmacological effects of kratom leaf have also been investigated, such as analgesic, stimulant, antidepressant, antioxidant, anti-inflammatory, antinociceptive, and antibacterial activities [5-8]. Alkaloid extracts from Mitragyna speciosa leaves show antidepressant effects and can reduce the effects of alcohol dependence [9]. Kratom has been suggested as a useful constituent in the treatment of opiate addiction as a replacement therapy [10]. The leaf also reported for its antitussive, anesthetic, antinociceptive,

Correspondence address:

Eki Juanda

E-mail : juandaeki48@gmail.com

Address : Faculty of Fisheries and Marine Sciences, University of Brawijaya, Veteran Malang, 65145 stimulant, analgesic, and narcotic-like action properties [10-12]. However, research on antimicrobial properties of the $M$. speciosa has been few reported. In this study, we report the antimicrobial and antioxidant activities of aqueous, methanolic, and alkaloids extracts of $M$. speciosa leaf.

Currently, the treatment of diseases caused by bacteria that are resistant to antibiotics requires new compounds that have high potential. Research on antibacterial properties is required to get new antibacterial compounds that have the potential to inhibit or kill antibioticresistant bacteria at an affordable price. One alternative that can be taken is to utilize active bacteria-killing substances contained in plants. This study aims to analyze the antibacterial activity of kratom leaf, measure the secondary compounds of kratom leaf extract, and measure the best concentration to kill Aeromonas hydrophilla.

\section{MATERIAL AND METHOD Material}

The materials used in this study are kratom leaves (Mitragyna speciosa Korth.) collected from Tanjung Jati Village, Putussibau Selatan District, Kapuas Hulu Regency, West Kalimantan Province in May 2019. The solvent used for extraction is methanol. The test bacteria used 
was Aeromonas hydrophilla. The medium used is Nutrient Agar (NA). $\mathrm{NaCl} 0.9 \%$ as a bacterial suspension. The chemicals used are hydrochloric acid, potassium hexa cyanated acid (III), iron (III) chloride, anhydrous acetic acid, chloroform, sulfuric acid, Dragendorff reagent, and Mayer reagent.

\section{Sample Collection and Preparation}

Fresh kratom leaves are collected and then wet sorted. After that, the leaves are washed and dried by shade drying in a room protected from direct sunlight. Furthermore, dried kratom leaves are sorted dry and cut into small pieces then grind till becoming Mitragyna speciosa Korth simplex powder.

\section{Extraction}

Simplisia powder (500 gram) was put into maceration vessels and macerated using methanol as a solvent $(1: 3 \mathrm{w} / \mathrm{v})$. The extraction process using the maceration method takes approximately 5 (five) days. Aqueous extract (maceration results) then filtered using filter paper and transferred into a container. The macerate is then concentrated using a rotary evaporator and followed by evaporation on a water bath until a thick methanol extract obtained. A total of $2.08 \mathrm{~kg}$ of Mitragyna speciosa Korth simplex powder. The dried one extracted using $96 \%$ methanol solvent. Solvent replacement every $1 \times 24$ hours and macerated for $7 \times 24$ hours. Macerate is concentrated with a rotary evaporator and water bath to obtain a thick extract.

\section{Phytochemical Screening}

Phytochemical screening carried out includes examination of alkaloids, flavonoids, steroids/ terpenoids, phenols, tannins, and saponins [13].

\section{Antibacterial Testing}

Testing the antibacterial activity of kratom leaf extract is carried out by the agar diffusion method using the NA medium. The bacterial suspension of 1:40 dilution of $0.02 \mathrm{ml}$ was mixed with $10 \mathrm{ml}$ of NA medium in a diluent bottle, shaken out to be homogeneous, and then poured into a petri dish. Wait until the medium is solid. The paper disc was dipped in the test solution and then placed on the surface of the NA medium, which was already solid and incubated at $37^{\circ} \mathrm{C}$ for 24 hours. Negative control using the paper disc dipped in distilled water. Testing the antibacterial activity of kratom leaf extract against Aeromonas hydrophila as carried out with 10 (ten) variations of concentration namely $3 \%$,
$6 \%, 9 \%, 12 \%, 15 \%, 18 \%, 21 \%, 24 \%, 27 \%$ and $30 \%$ [16].

\section{RESULT AND DISCUSSION}

\section{Extraction Result and Secondary Metabolites}

The extraction process obtained blackishbrown extract with 62.27 grams of extract and extract yield percentage of $31.14 \%$. The results of the identification of secondary metabolites of kratom leaf methanol extract obtained positive results of alkaloid compounds, saponins, tannins, phenolics, steroids, and triterpenoids. Secondary metabolite test results can be seen in Table 1.

Table 1. Secondary metabolites content of kratom leaf extract.

\begin{tabular}{cc}
\hline extract. & Result \\
Parameter & + \\
Alkaloids & + \\
Flavonoids & + \\
Saponins & + \\
tannins & + \\
phenol & + \\
Steroid/terpenoids & + \\
\hline
\end{tabular}

Based on the results of phytochemical screening stated that the kratom leaf methanol extract contains secondary metabolites of the alkaloid, flavonoid, steroid/terpenoid, phenol, tannins, and saponin groups. The results of this study support the results of previous studies, which stated that kratom leaf methanol extracts contain high concentrations of secondary metabolites of alkaloids and flavonoids, while tannins and steroids detected with low concentrations [7]. The main compounds in Mitragyna speciosa are alkaloids, triterpenoids, and flavonoids [14]. Besides alkaloids, kratom leaves also contain flavonoids, saponins, triterpenoids, and glycoside derivatives[15].

\section{Antibacterial Activity of Kratom Leaf}

The results of the antibacterial activity test showed that kratom leaf extract has antibacterial activity against Aeromonas hydrophila, which is characterized by a kill zone around the paper disc. A negative control that is distilled water does not produce a kill zone around the paper disc, so it means that distilled water has no antibacterial activity, and methanol extract of kratom leaf has antibacterial activity.

The killing zones that formed around the paper disc can be categorized base on the strength of the antibacterial activity of the extract. If the area of the resistance zone is 20 $\mathrm{mm}$ or more, it categorized in a powerful activity, between $10-20 \mathrm{~mm}$ is categorized in a strong activity, between $5-10 \mathrm{~mm}$ is categorized in the 
moderate category and area barriers of $5 \mathrm{~mm}$ or less are included in the weak [16]. The measurement data of the kill zone of the methanol extract of kratom leaves can show in Table 2.

Table 2. The data of the kill zone of the extract of kratom leaves compare the negative control

\begin{tabular}{ccc}
\hline Sample & $\begin{array}{c}\text { Concentration } \\
\text { (\%) }\end{array}$ & $\begin{array}{c}\text { Average kill zone diameter } \\
\text { against } \begin{array}{c}\text {. hydrophilla } \\
\text { (mm) }\end{array}\end{array}$ \\
\hline & 3 & 0 \\
& 6 & 0 \\
& 9 & 6.32 \\
Kratom & 12 & 6.44 \\
Extract & 15 & 6.98 \\
& 18 & 7.32 \\
& 21 & 8.09 \\
& 24 & 9.55 \\
& 27 & 8.96 \\
Negative & 30 & 8.23 \\
control & 0 & \\
(Distilled & & \\
water) & & \\
\hline
\end{tabular}

Table 2 shows that the antibacterial activity of methanol extracts kratom leaf against $A$. hydrophilla at concentrations of $3 \%$ and $6 \%$ did not have inhibitory zones by concentrations of $9 \%, 12 \%, 15 \%, 18 \%, 21 \%, 27 \%$ and $30 \%$ included in the medium category. The best concentration was at $24 \%$. Antibacterial activity test shows that increasing the concentration of extract given can increase the killing power of the extract against bacteria. However, if the concentration of the extract continues to increase, it can reduce the killing power. We assume that this is because an increase in concentration can lead to an increase in the viscosity of the extract, thus affecting the rate of diffusion of the extract in agar media. In addition to the concentration factor, the type of antimicrobial material can also determine the ability to inhibit bacterial growth [17]. In this study, we assumed that the antibacterial activity of kratom leaf extract was due to the presence of alkaloid compounds. Alkaloid compounds are lipophilic substances that are known to act as antimicrobials against bacteria, fungi, viruses, and protozoa by damaging bacterial cell membranes [18].

\section{CONCLUSION}

Secondary metabolites of kratom leaf methanol extract obtained positive results of alkaloid compounds, saponins, tannins, phenolics, steroids, and triterpenoids. Kratom leaf extract has antibacterial activity against
Aeromonas hydrophilla, which is characterized by a kill zone around the paper disc. The best concentration that shows a wide killing zone was $24 \%$ of the extract.

\section{REFERENCES}

[1] Hassan, Z., M. Muzaimi, V. Navaratnam, N. H. Yusoff, F.W. Suhaimi, R. Vadivelu, ... C.P. Müller. 2013. From Kratom to mitragynine and its derivatives: Physiological and behavioural effects related to use, abuse, and addiction. Neurosci. Biobehav. Rev. 37(2). 138-151.

[2] Ridayani, Y., M. Andrie, B. Wijianto. 2013. Uji efek sedatif fraksi etanol daun kratom (Mitragyna speciose Korth.) pada mencit Jantan Galur BALB/c. IPI Jurnal Mahasiswa Fakultas Kedokteran UNTAN. 3. 1-9.

[3] Warner, M.L., N.C. Kaufman, O. Grundmann. 2015. Review: The pharmacology and toxicology of kratom : from traditional herb to drug of abuse. Int. J. Leg. Med. 130(1). 127-138.

[4] Jansen, K.L, C.J. Prast. 1988. Ethnopharmacology alkaloids of kratom and the Mitragyna alkaloids. J. Ethnopharmacol. 23. 115-119.

[5] Reanmongkol, W., N. Keawpradub, K. Sawangjaroen. 2007. Effects of the extracts from Mitragyna speciose Korth. leaves on analgesic and behavioral activities in experimental animals. J. Sci. Tech. 29. 3948.

[6] Idayu, N.F., M.T. Hidayat, M.A. Moklas, F. Sharida, A.R. Raudzah, A.R. Shamima, E. Apryani. 2011. Antidepressant-like effect of mitragynine isolated from Mitragyna speciosa Korth in mice model of depression. Phytomedicine. 18. 402-407.

[7] Mossadeq, W.M.S., M.R. Sulaiman, T.A.T. H.S. Mohamad Chiong, Z.A. Zakaria, M.L. M.T.H. Jabit Baharuldin, D.A. Israf. 2009. Anti-Inflammatory and Antinociceptive Effects of Mitragyna speciosa Korth. Med. Princ. Pract. 18. 378-384.

[8] Parthasarathy, S., J. Bin Azizi, S. Ramanathan, S. Ismail, S. Sasidharan, M.I.M. Said, S.M. Mansor. 2009. Evaluation of antioxidant and antibacterial activities of aqueous, methanolic and alkaloid extracts from Mitragyna Speciosa (Rubiaceae family) leaves. Molecules. 14. 3964-3974.

[9] Cheaha, D., N. Keawpradub, K. Sawangjaroen, P. Phukpattaranont, E. Kumarnsit. 2015. Effects of an alkaloid-rich 
extract from Mitragyna speciosa leaves and fluoxetine on sleep profiles, EEG spectral frequency and ethanol withdrawal symptoms in rats. Phytomedicine. 22(11). 1000-1008.

[10] Idid, S.Z., L.B. Saad. 1988. Evaluation of analgesia induced by mitragynine, morphine and paracetamol on mice. ASEAN Review of Biodiversity and Environmental Conservation: Bangi, Malaysia. 1-7.

[11] Macko, E., J.A. Weisbach. 1972. Some observations on the pharmacology of mitragynine. Arch. Int. Pharmacodyn. Ther. 198. 145-161.

[12] Perry, L.M. 1980. Medicinal plants of East and Southeast Asia. MIT Press. Cambridge, MA, USA.

[13] Hanani, E. 2015. Analisis Fitokimia. EGC. Jakarta.

[14] Gong, F., H.P. Gu, Q.T. Xu, W.Y. Kang. 2012. Genus Mitragyna: ethno-medical uses and pharmacological studies. J. Phytopharmacol. Inforesights Publishing, 3(2).

[15] León, F., E. Habib, J.E. Adkins, E.B. Furr, C.R. McCurdy, S.J. Cutler. 2009. Phytochemical characterization of the leaves of Mitragyna speciosa grown in U.S.A. Nat. Prod. Commun. 4(7).

[16] Munawwarah, L., A.M. Ramadhan, M. Ardana. 2016. Uji Aktivitas antibakteri ekstrak daun Sapat (Mitragyna Speciosa Korth.) terhadap bakteri Escherichia Coli dan Staphylococcus aureus. Proceeding of the $4^{\text {th }}$ Mulawarman Pharmaceuticals Conferences. doi: 10.25026/mpc.v4i1.179.

[17] Ajizah, A. 2004. Sensitivitas Salmonella typhimurium terhadap ekstrak daun Psidium guajava. J. Bioscientiae. 1(1). 31-38.

[18] de-Fatima, A., L.V. Madolo, L.S. Conegero, R.A. Pilli, C.V. Ferreira, L.K. Kohn, J.E. deCarvalho. 2006. Lactones and their derivatives: biological activities, mechanisms of action and potential leads for drugs design. J. Med. Chem. 13. 33713384. 